\author{
Małgorzata Czerny \\ Poznan University of Economics and Business \\ Faculty of Management \\ e-mail: malgorzata.czerny@ue.poznan.pl
}

\title{
Wpływ zasad religijnych na ukształtowanie systemu rachunkowości*
}

\section{The Influence of Religious Principles on the Formation of the Accounting System}

Undoubtedly, such factors as different cultural background affects 'the shape' of economy. The impact of cultural factors on the economy, as well as its specific fields (particularly accounting), has been studied by, among others, Mueller, Hofstede and Gray. Reflections on the topic were also conducted in Polish literature, although relatively late. One of the cultural factors is, beyond doubt, religion, forming some ethical attitudes through the transfer of certain values, which become a guide to individual actions, and exerting an obvious influence on the applicable standards in a society. The author does not pretend to consider the relations between religion and ethics, in the article only issues concerning possible to demonstrate influence of religious norms on accounting are raised. The aim is briefly to discuss the impact of Christianity, Islam and Confucianism on accounting systems and practices, based on literature studies. In conclusion, the question arises about the sense of the convergence of accounting standards, at least in the context of the current efforts undertaken in this field.

Keywords: ethics, religion, accounting

JEL Classification: M41, N20, Z12

\footnotetext{
* Artykuł opublikowany w ramach projektu „Popularyzacja najnowszej wiedzy ekonomicznej wśród ludzi młodych" realizowanego z Narodowym Bankiem Polskim w ramach programu edukacji ekonomicznej.
} 


\section{Wstęp}

Nie ulega wątpliwości, że czynniki takie, jak odmienne uwarunkowania kulturowe, wywierają wpływ na kształt gospodarki. Wpływ uwarunkowań kulturowych na ekonomię, jak i jej poszczególne dziedziny, w tym rachunkowość, był badany m.in. przez G. Muellera, G. Hofstede'a, a następnie przez S.J. Graya ${ }^{1}$. Rozważania na ten temat prowadzone były także w polskiej literaturze przedmiotu, jakkolwiek stosunkowo późno ${ }^{2}$. Jednym z czynników kulturowych jest niewątpliwie religia, kształtująca pewne postawy etyczne poprzez przekaz określonych wartości, które stają się wytyczną działania poszczególnych jednostek oraz wywierają ewidentny wpływ na normy obowiązujące w danym społeczeństwie. Autorka nie rości sobie pretensji do snucia rozważań dotyczących powiązań między religią a etyką, w tym etyką biznesu, a w artykule poruszone są jedynie zagadnienia dotyczące możliwego do wykazania wpływu norm religijnych na kształt rachunkowości. Na podstawie przeprowadzonych studiów literatury przedmiotu pokrótce omówiony został wpływ chrześcijaństwa, islamu oraz konfucjanizmu na praktyki rachunkowości, a tym samym na ukształtowanie się jej systemu.

Czynniki kulturowe, społeczne, ekonomiczne, polityczne (odmienne w wielu krajach) mają znaczący wpływ na oczekiwania formułowane wobec sprawozdań finansowych pod kątem informacji, których powinny one dostarczać, a także zadań stawianych przed systemem rachunkowości. Każdy kraj wykorzystuje system rachunkowości - mimo jego posuniętej daleko standaryzacji - w sposób dostosowany do specyfiki owych czynników; między innymi współgrający z ogólnymi zasadami, na których oparte jest działanie systemu gospodarczego ${ }^{3}$.

\footnotetext{
${ }^{1}$ G. Mueller, International Accounting, Macmillan, New York 1967; G. Hofstede, Culture's Consequences: International Differences in Work-Related Values, Sage, Beverly Hills-London 1980; idem, Cultural dimensions in management and planning, „Asia Pacific Journal of Management” 1984, vol. 1, nr 2, s. 81-99; S.J. Gray, Towards a Theory of Cultural Influence on the Development of Accounting System Internationally, ,Abacus” 1988, vol. 24, nr 1, s. 1-24, doi: 10.1111/j.1467-6281.1988.tb00200.x. ${ }^{2}$ Cf. A. Kamela-Sowińska, Rachunkowość od antropologii do międzynarodowych standardów [w:] Rachunkowość w zarządzaniu jednostkami gospodarczymi, red. T. Kiziukiewicz, Katedra Rachunkowości Uniwersytetu Szczecińskiego, Katedra Rachunkowości Akademii Rolniczej w Szczecinie, Szczecin 2006; J. Adamek Rachunkowość w kręgu kultury islamskiej, „Zeszyty Teoretyczne Rachunkowości” 2009, t. 49 (105), s. 7-17; idem, Kulturowe uwarunkowania krajowych systemów rachunkowości w świetle koncepcji wymiarów subkultury rachunkowości S. Graya, „Zeszyty Teoretyczne Rachunkowości” 2011, t. 62 (118), s. 7-22; idem, Kultura a rachunkowość [w:] Finanse i rachunkowość - teoria i praktyka, Prace Naukowe Uniwersytetu Ekonomicznego we Wrocławiu, nr 193, Wrocław 2011; idem, Kulturowe uwarunkowania rachunkowości $w$ świetle założeń i praktyki rachunkowości islamskiej $i$ chińskiej, CeDeWu, Warszawa 2012; M.A. Bonca, Islamskie instrumenty finansowe, Wydawnictwa Akademickie i Profesjonalne, Akademia Leona Koźmińskiego Warszawa 2010.

Często prowadzone są rozważania odnośnie do zasad etycznych zawodu audytora lub księgowego. Cf. E.I. Szczepankiewicz, Wybrane aspekty i uwarunkowania realizacji zasad etyki przez audytorów wewnętrznych, „Monitor Rachunkowości i Finansów” 2007, nr 9; E.I. Szczepankiewicz, M. Dudek, Etyka $w$ dziataniu audytora wewnętrznego [w:] Etyka $w$ procesie kształcenia i gospodarowania, red. A. Kamela-Sowińska, Zeszyty Naukowe Wyższej Szkoły Handlu i Rachunkowości w Poznaniu, Poznań 2007.

${ }^{3}$ Cf. J. Adamek, Kulturowe uwarunkowania..., s. 28-38, 122; P. Diaconau, N. Norman, Accounting Research from the Globalization Perspective, „International Journal of Human and Social Sciences” 2006, vol. 1 , nr 1, s. 30 .
} 
Konieczność zachowania wysokich standardów etycznych w rachunkowości, rozumianej jako szczególny system informacyjno-kontrolny o charakterze retroi prospektywnym, dostosowany do celów szeroko pojętego zarządzania finansami podmiotu gospodarczego (organizacji), jest podkreślana bardzo mocno zarówno w literaturze przedmiotu, jak i przez praktykę gospodarczą. $Z$ uwagi na rolę, jaką ma do spełnienia rachunkowość, rzetelność dostarczanych przez nią informacji jest warunkiem sine qua non jej istnienia i zapotrzebowania na generowane przez ten system dane. Jest to także niezbędne dla uzasadnienia uprzywilejowanego statusu zawodu księgowego w służbie publicznej - jego podstawą jest zaufanie i uczciwość ${ }^{4}$. Etyka jednostki to wewnętrzny system przekonań, decydujący o tym, jak postrzega ona świat; wpływ środowiska zewnętrznego jest tu bezdyskusyjny. Kultura i etyka są zbieżne; etyka danej osoby kształtuje się w oparciu o kulturę grupy, do której przynależy i z którą się identyfikuje. Wyznacznikiem właściwych zachowań etycznych są zaś w dużej mierze przekonania religijne ${ }^{5}$.

Rozwój systemów rachunkowości w krajach o odmiennych uwarunkowaniach kulturowych, gdzie systemy wartości kształtowały się w oparciu o wierzenia chrześcijańskie, islam, czy wreszcie filozofię konfucjańską lub buddyzm, wskazuje na to, że religia jednoznacznie (choć w różnorodnym stopniu) wpływa na praktykę w tym zakresie.

\section{Chrześcijaństwo a „zachodni” model rachunkowości}

Na chrześcijańskim sposobie pojmowania i oceny waży mocno idea wczesnochrześcijańskiego, a następnie rzymskokatolickiego sacrum-profanum. Każde działanie i aktywność w przeszłości były jednoznacznie definiowane jako święte i nienaruszalne (sacrum) lub doczesne (profanum). Pieniądze i wszystko, co się z nimi wiąże, uznane zostały za ,światowe” (sfera profanum) ${ }^{6}$. Pewnym usprawiedliwieniem dla

\footnotetext{
${ }^{4}$ Zaufanie to zostało w ostatnich latach nadszarpnięte przez szereg upublicznionych skandali finansowych (np. sprawa Enronu). Cf. D. Satava, C. Caldwell, L. Richards, Ethics and Auditing Culture: Rethinking the Foundation of Accounting and Auditing, ,Journal of Business Ethics” 2006, vol. 64, nr 3, s. 271-284, doi: 10.1007/s10551-005-0556-y.

Źródła upatrywać można w połowie lat 90. ubiegłego wieku, kiedy (przede wszystkim w USA) dokonała się gruntowna zmiana w biznesowym systemie wartości - wartości etyczne z absolutnych (których gruntem było judeochrześcijaństwo) ewaluować poczęły w stronę relatywizmu. Cf. V. Onyebuchi, Ethics in accounting, ,International Journal of Business and Social Science” 2011, vol. 2, nr 10, s. 275276; G. Lehman, Accounting, Accountability and Religion: Charles Taylor's Catholic Modernity and the Malaise of a Disenchanted World, University of South Australia, School of Accounting, Singapore: Fourth Asia Pacific Interdisciplinary Research in Accounting Conference 2004.

${ }^{5}$ Etyka zdefiniowana przez Onyebushi to systematyczne badania nad postępowaniem w oparciu o zasady moralne, wybory poprzedzone refleksja, i pozytywne oraz negatywne wzorce zachowania. Cyt. za: M. Young, Cultural Influences on Accounting and Its Practices 2013, s. 27, http://digitalcommons.liber ty.edu/cgi/viewcontent.cgi?article=1396\&context=honors (data dostępu: 6.07.2015). Cf. T. Wiseman, A. Young, Religion: productive or unproductive?, „Journal of Institutional Economics” 2014, vol. 10, nr 1, s. 21-45, doi: 10.1017/S174413741300026X.

${ }^{6}$ Przekonanie to oprzeć można na wersecie Ewangelii Św. Mateusza (6:24): Nikt nie może dwom panom służyć (...) Nie możecie służyć Bogu i Mamonie (Biblia Tysiąclecia, wyd. III, Wydawnictwo Pallottinum, Poznań-Warszawa 1982, s. 1130).
} 
aktywności gospodarczej, w tym rachunkowości, jako świeckiej praktyki mającej związki z jednoznacznie potępianą i zakazaną przez Kościół lichwą, było wspieranie sacrum (dzieła Bożego, aktywności Kościoła) poprzez dostarczanie środków na jego funkcjonowanie (poprzez donację, zakup odpustów) ${ }^{7}$.

Nową perspektywę w postrzeganiu działalności gospodarczej wyznaczył protestantyzm. Zalecenia chrześcijaństwa zreformowanego można by ująć hasłowo w cytacie z listu do Św. Pawła do Koryntian (10:31): cokolwiek (...) czynicie, czyńcie na chwatę boża ${ }^{8}$. Każdy przejaw ludzkiej aktywności może być zatem potraktowany jako działanie na chwałę Bożą, zależnie od intencji.

Klasyczna ekonomia XVIII wieku oparta była w dużej mierze właśnie na etyce protestanckiej, gloryfikującej pracowitość i pochwalającej gromadzenie i pomnażanie bogactwa uzyskanego dzięki ciężkiej pracy (w odróżnieniu od etyki katolickiej, podkreślającej raczej cnoty ,pozautylitarne”). Jak pisze Nasr, etyczne, religijne korzenie zachodniej ekonomii zostały dość szybko zmarginalizowane 9 .

Pierwotny podział na sacrum i profanum z jednej strony, a usprawiedliwienie dla gromadzenia dóbr doczesnych z drugiej, zaważyły silnie na całej kulturze Zachodu. W miarę rozwoju cywilizacji zachodniej, stawała się ona coraz bardziej materialistyczna. Wiara nie miewa już skutków politycznych czy gospodarczych w tym samym wymiarze, co dawniej ${ }^{10}$. W zasadzie począwszy od końca średniowiecza instytucje chrześcijańskie przestały stopniowo podkreślać integralność wiary chrześcijańskiej z działalnością biznesową, nawet w kontekście służby publicznej. Świecka kultura zachodnia, której implikacje zaznaczone zostały we wstępie do niniejszego artykułu, „uwolniła” poniekąd biznes (a także rachunkowość) od moralności religijnej opartej na m.in. empatii, uwzględnieniu w swoich zachowaniach praw innych ludzi czy coraz bardziej abstrakcyjnego „dobra społecznego" 11 . Fakt ten miał poważne konsekwencje dla współczesnych praktyk biznesowych w kręgu kultury zachodniej. Konsekwencją było ,,przeorientowanie” biznesu w tym również zawodowych księgowych - z perspektywy „służby społecznej” na „osobiste osiągnięcia” i ,zarabianie pieniędzy”, będące wyznacznikiem sukcesu zawodowego i statusu społecznego. Jeśli etyczne normy, w tym osobiste poglądy na to, co dobre a co złe, stają się względne, pozwala to w zgodzie z własnym sumieniem podejmować decyzje na podstawie własnych opinii, abstrahując od zasad

\footnotetext{
${ }^{7}$ S. Carmona, M. Ezzamel, Accounting and Religion: A Historical Perspective, „Accounting History” 2006, vol. 11, nr 2, s. 117-127, doi: 10.1177/1032373206063109 [za:] M. Young, op. cit., s. 35-36.

${ }^{8}$ Biblia Tysiąclecia, op. cit., s. 1300.

${ }^{9}$ Według tego autora, publikacje prac Smitha, Ricardo, J.S. Milla, przedstawiających swoje koncepcje ekonomiczne, podkreślające ,nadmiernie” znaczenie akumulacji bogactwa na równi z przedsiębiorczością (które to pojęcie zatracało swój pierwotny sens ,,aktywności gospodarczej”, będąc utożsamiane coraz powszechniej po prostu z umiejętnością „dorobienia się”), doprowadziły do tego, że ekonomia stała się z jednej strony dyscypliną naukową, z drugiej zaś - formą działalności społecznej, jeśli nie oderwaną od etyki, to w każdym razie rozmijającą się z nią coraz częściej. S.H. Nasr, A Young Muslim's Guide to The Modern World, Cambridge 1993, s. 205.

${ }^{10}$ H.B. Afifuddin, A.K. Siti-Nabiha, Towards Good Accountability: The Role of Accounting in Islamic Religious Organisations, „World Academy of Science, Engineering and Technology. International Journal of Social, Behavioral, Educational, Economic, Business and Industrial Engineering” 2010, vol. 4, nr 6, s. 1143 i n.

${ }^{11}$ Ibidem, s. 1143.
} 
ogólnych, co potencjalnie prowadzi do korupcji. Jeśli relatywizm staje się normą, ludzie znajdują sposoby obejścia prawa, nie odczuwając przy tym dyskomfortu sumienia. Osoba przyjmująca taki system etyczny przyjmuje jednocześnie założenie, że zasady działają inaczej w biznesie niż w innych aspektach życia. Model ten jest oparty na samooszukiwaniu i „abstrakcyjnej chciwości”"12.

Ekonomia liberalizmu, w ramach której kształtował się zachodni model rachunkowości, stanowi w gruncie rzeczy wypadkową pomysłów pochodzących z różnych źródeł (jak neoklasyczna szkoła ekonomii, prace A. Smitha, czy M. Friedmana $)^{13}$. Obecne zasady tej tradycji można ująć następująco:

(1) prawo własności prywatnej,

(2) indywidualizm,

(3) korzyść własna (którą można również postrzegać jako interesowność, egoizm),

(4) racjonalność,

(5) samoregulacja rynku.

Społeczeństwo kapitalistyczne opiera się na doktrynie indywidualnej własności prywatnej. Uznaje własność publiczną jedynie wówczas, gdy jest to niezbędne (np. wymaga tego dobro społeczne), a państwową, gdy doświadczenie wskazuje na konieczność nacjonalizacji pewnych gałęzi gospodarki. Poszanowanie własności prywatnej jest jedną z najważniejszych podstawowych zasad liberalizmu, która wpływa na system rachunkowości i jej standardy. Model zachodni rachunkowości bazuje obecnie na mikroekonomii ${ }^{14}$. Zatem rachunkowość koncentruje się na przedsiębiorstwie jako jednostce, która wpływa poprzez swe działania na rynku na całą gospodarkę i dostarczaniu informacji finansowych dla inwestorów i wierzycieli oraz kadry menedżerskiej. System rachunkowości w krajach zachodnich cechuje orientacja rynkowa. Z uwagi na to, że w gospodarce liberalnej jako główne cele gospodarowania jawią się maksymalizacja zysku i indywidualizacja korzyści, uwaga rachunkowości jako systemu informacyjnego skupia się na rachunku zysków i strat, oceniając firmę pod kątem przychodów i wydatków (cechuje ją zatem podejście przychodowo-kosztowe przy ustalaniu dochodów) ${ }^{15}$. Podobnie jak cały system gospodarczy, rachunkowość opiera się na teorii podmiotu (The Entity Theory). Podstawą biznesu, wyznaczającą jednocześnie jego ramy prawne, jest świeckość, a wraz z nią swoista - wspomniana już powyżej - dychotomia pomiędzy biznesem a moralnością - co dotyczy również systemu rachunkowości, ukształtowanego w ramach liberalnej gospodarki. Polityka rachunkowości zorientowana jest przede wszystkim na cele (w dużo mniejszym stopniu na wartość), podejście do zasad rachunkowości jest czysto techniczne, aczkolwiek ograniczane przez kodeksy etyki zawodowej. W modelu tym pojęcie wartości pieniądza w czasie jest powszechnie

${ }^{12}$ D. Satava, C. Caldwell, L. Richards, op. cit., s. 273.

${ }^{13}$ R. Holton, Economy and Society, Routledge, UK 1992, s. 54-69.

${ }^{14} \mathrm{Cf}$. E. Jaworska, Specyfika rachunkowości islamskiej. Wybrane zagadnienia [w:] Finanse, rynki finansowe, ubezpieczenia, Zeszyty Naukowe Uniwersytetu Szczecińskiego nr 32, Wydawnictwo Uniwersytetu Szczecińskiego, Szczecin 2011; M.R. Taheri, The Basic Principles of Islamic Economy and Their Effects on Accounting Standards-Setting 2011, http://www.docstoc.com/docs/166485067/The-basic-principles-ofIslamic-economy-and-their-effects-on-accountingstandards-setting (data dostępu: 3.12.2014).

15 Ibidem. 
uznawane i wykorzystywane, a oprocentowanie jak najbardziej dopuszczalne ${ }^{16}$. Jeśli chodzi o rodzaj identyfikowanych przez system rachunkowości informacji - są to wewnętrzne, materialne zdarzenia gospodarcze podlegające pomiarowi pieniężnemu, przy zachowaniu zasady ograniczoności ujawnień, pomiar oparty jest zaś głównie na koszcie historycznym.

\section{Wpływ zasad religijnych islamu na uksztaltowanie systemu rachunkowości oraz sprawozdawczości finansowej w krajach muzułmańskich}

Islam jest, jak podkreślają sami wyznawcy, czymś więcej aniżeli tylko religią - jest to jednocześnie kultura, światopogląd i styl życia, którego wierni powinni bezwzględnie przestrzegać ${ }^{17}$. Islam jak być może żadna inna religia ingeruje we wszelkie przejawy aktywności wyznawców ${ }^{18}$, a zatem również wpływa na sposób prowadzenia działalności gospodarczej. Unikalne rozwiązania w sposobie prowadzenia biznesu i w dziedzinie praktyk księgowych w społeczeństwie muzułmańskim są doskonałym przykładem na to, jak dalece księgowość może być zintegrowana $\mathrm{z}$ fundamentalnymi zasadami religijnymi ${ }^{19}$. W islamie nie funkcjonuje pojęcie $s a$ crum i profanum, sfery te przenikają się nawzajem. Życie doczesne wiąże się ze sferą duchową i religijną, codzienne postępki przygotowują niejako wiernego do aktów „wyższych”, o wymiarze duchowym. Dotyczy to także aktywności gospodarczej, a zatem i rachunkowości ${ }^{20}$. Limitowana prawem religijnym gospodarka islamu funkcjonuje w oparciu o trzy podstawowe zasady ${ }^{21}$ :

(1) wieloaspektowości własności (jej złożoności i niejednorodności),

(2) wolności gospodarczej w ramach określonego limitu,

(3) sprawiedliwości społecznej.

Prawo Sharia'h formułuje szczególne postulaty w odniesieniu do praktyk finansowych, bezwzględnie obowiązujące wyznawców i decydujące o oryginalnym, odmiennym od modelu zachodniego, funkcjonowaniu systemów gospodarczych w krajach muzułmańskich. Postulaty te mają również istotny wpływ na standardy rachunkowości, jej praktyki oraz kształt sprawozdań finansowych. Sprowadzić je można do trzech zakazów:

(1) zakazu riby (pobierania odsetek) - braku możliwości stosowania stopy procentowej,

\footnotetext{
${ }^{16}$ M.A. Bonca, op. cit. s. 50 i n.; E. Jaworska, op. cit. s. 80.

${ }^{17}$ S. Hamid, R. Craig, F. Clarke, Religion: A Confounding Cultural Element in the International Harmonization of Accounting?, ,Abacus” 1993, vol. 29, nr 2, s. 131-148, doi: 10.1111/j.1467-6281.1993.tb00427.x. ${ }^{18}$ Muzułmanie wierzą, podobnie zresztą jak chrześcijanie, że ze swych uczynków będą zdawać sprawę Bogu w Dniu Sądu, otrzymując odpowiednio nagrody bądź kary. Dlatego też muszą przestrzegać prawa Sharia'h w każdym momencie i aspekcie życia. Sharia'h na równi z Koranem tworzy uznawany powszechnie kodeks norm etycznych, określających arbitralnie, co dobre, a co złe w oczach Boga.

${ }^{19}$ B. Maali, C. Napier, Accounting, Religion and Organisational Culture: The Creation of Jordan Islamic Bank, „Journal of Islamic Accounting and Business Research”2010, nr 1(2), s. 6-11.

${ }^{20}$ H.B. Afifuddin, A.K. Siti-Nabiha, op. cit., s. 1134 i n.

${ }^{21}$ M.B. Sadr, Iqtisaduna (Our Economic), $2^{\text {nd }}$ Edition, Teheran 1994, s. 51-55.
} 
(2) zakazu gharar (spekulacji) - wszelka aktywność pociągająca za sobą ryzyko spekulacyjne jest zakazana i wierny jest zobowiązany jej unikać; szczególnie haniebna jest spekulacja artykułami pierwszej potrzeby i dobrami naturalnymi,

(3) zakazu zaangażowania w wytwarzanie bądź konsumpcję dóbr będących haram (zakazanymi z punktu widzenia religii),

i jednego nakazu - uiszczania zakat, będącego obligatoryjnym rodzajem podatku w krajach muzułmańskich ${ }^{22}$.

System rachunkowości w krajach muzułmańskich ukształtował się i rozwijał w oparciu o powyższe zasady, stąd jego daleko idąca odmienność od standardów zachodnich. Podstawowa rozbieżność w postrzeganiu konieczności przestrzegania określonych standardów i rozwiązań, ich stanowieniu i dopracowywaniu pomiędzy przedstawicielem świata islamu a ,Zachodu” wynika z zupełnie odmiennego postrzegania prawa. Na Zachodzie przepisy powstają w celu dostosowania do istniejącej sytuacji, unormowania jej, podczas gdy w ocenie muzułmanina, to raczej zaistniałe sytuacje należy odpowiednio „kształtować” w celu dostosowania do Prawa Bożego $^{23}$. Przy czym podobnie jak to ma miejsce we wszystkich głównych religiach, islam wymaga od ludzi etycznych zachowań w kontaktach z innymi (odpowiedzialność i etyka są wysoko cenione w tej kulturze) i poszanowania zasobów.

Islam akceptuje własność w różnych formach, bez faworyzowania żadnej $\mathrm{z}$ nich ${ }^{24}$. Własność należy do Boga, człowiek jest jedynie jej powiernikiem; z tytułu dysponowania własnością wynikają zobowiązania wobec innych ludzi i ich praw; jednak zakres własności (każdego rodzaju) może ulec zmianie i interpretowany jest w zależności od potrzeb i okoliczności ${ }^{25}$. Pośrednio wynika stąd zasada ograniczonej wolności gospodarczej. Każdy człowiek jest strażnikiem zaufania społecznego, a jego prawo własności powinno być ograniczane w interesie publicznym. Sukces jednostki i społeczeństwa zależy od równowagi między potrzebami duchowymi a materialnymi człowieka. System dystrybucji dóbr i kapitału w społeczeństwie islamskim przewiduje różnice w zamożności, jednak odrzuca nadmierne rozwarstwienie społeczne. Sprawiedliwa dystrybucja dochodów realizowana jest dzięki

\footnotetext{
${ }^{22}$ Cf. A. Samad, Performance of Interest-free Islamic Banks vis-à-vis Interest-based Conventional Banks of Bahrain, „IIUM Journal of Economics and Management” 2004, vol. 12, nr 2, s. 3-5; M.S. Moin, Financial Performance of Islamic Banking and Conventional Banking in Pakistan: A Comparative Study, ,International Journal of Innovative and Applied Finance” 2013, vol. 1, nr 1, s. 4-5, M.A. Bonca, op. cit., s. 5052, 66-81; J. Adamek, Kulturowe uwarunkowania..., s. 47 i nast.; M. Czerny, Wplyw zasad religijnych islamu na sprawozdania finansowe - zarys problemu, „Teoria i historia rachunkowości”, materiały konferencyjne UEP „Rachunkowość Warta Poznania”, Poznań 2015, s. 22-23, 25.

${ }^{23}$ M.R. Taheri, op. cit., s. 5. Cf. M. Mutahhari, Islamic Economic, Sadra Pub., Teheran 1993, s. 206.

${ }^{24}$ M.B. Sadr, op. cit., s. 98-114.

${ }^{25}$ Pomiędzy prawnikami i ekonomistami muzułmańskimi trwa m.in. dyskusja, czy państwo może wymusić określony przepływ dóbr i kapitału i ich dystrybucję zgodnie z wymogami sprawiedliwości społecznej, od zamożnych do najuboższych i najbardziej potrzebujących obywateli, czy też winno się to odbywać jedynie ,poprzez perswazję”. Za: S. Rahman, Islamic Accounting Standards, 1997, http://www .ifew.com/insight/13036mon/accstds.htm (data dostępu: 04.12.2014), s. 3 i n. Cf. U. Chapra, The Islamic Welfare State and its Role in the Economic Studies in Islamic Economics [w:] Studies in Islamic Economics, red. A. Khurshid, Redwood Burn, Leicester 2006; A. Shari'ati, Abu Zar (Companion of the Prophet ), Ershad Pub., Teheran 1987; M.N. Siddiqi, Muslim Economic Thinking: A Survey of Contemporary Literature, The Islamic Foundation, United Kingdom 1981.
} 
zakazowi pobierania odsetek i obligatoryjnemu podatkowi zakat. Rachunkowość zatem powinna dostarczać informacji finansowych istotnych przede wszystkim dla rządu i społeczeństwa jako ogółu (głównych użytkowników sprawozdań finansowych). Podstawowymi zagadnieniami są zaś wpływy z podatków takich jak zakat ${ }^{26}$ i innych, oraz sposób ich wydatkowania przez państwo. Muzułmański model rachunkowości opiera się zatem na makroekonomii.

W skali mikro, islamskie sprawozdania finansowe muszą dostarczać informacji o znaczeniu ekonomicznym i społecznym podjętych w jednostce gospodarczej decyzji ${ }^{27}$, przydatnych do oceny kierownictwa, oraz wysiłków podjętych przez wszystkich pracowników przedsiębiorstwa dla wykorzystania zasobów niezbędnych do osiągnięcia celu przedsiębiorstwa i celów społecznych, zgodnie z normami prawnymi i etycznymi. Ponadto sprawozdanie finansowe winno dostarczać informacji pozwalających na ocenę efektywności zarządzania w zakresie podziału dochodów pod kątem osiągnięcia ekonomicznej sprawiedliwości. W sprawozdaniu finansowym zawarty powinien być pełny i rzetelny obraz przedsiębiorstwa i jego działalności, zgodnie z zasadami zawartymi w Sharia ' $h$. Wszystkie rodzaje działalności, które są niezgodne z tym prawem (haram), a zatem nielegalne i niemoralne, powinny być ujawnione ${ }^{28}$. W tym punkcie prawo Sharia'h jest zgodne ze znaną i uznawaną w świecie zachodnim zasadą true and fair view.

Drugą z cech charakterystycznych tego systemu rachunkowości jest oparcie na teorii własności. Wynika to stąd, że w świetle islamu jako kanonu zasad, każdy jest odpowiedzialny za swoje czyny - zaniechania religijne, a także za działalność gospodarczą i finansową, w jaką się zaangażował. Pomiędzy przedsiębiorstwem jako jednostką gospodarczą, a jej posiadaczem nie powinno być rozdzielności. Jako właściciel aktywów, odpowiada on za zobowiązania i wierzytelności. Niemoralne byłoby zwolnienie go z odpowiedzialności za długi firmy, przy zachowaniu prawa do zysku. Byłby to rodzaj zakazanej spekulacji (możliwość uzyskania korzyści nadmiernych w stosunku do ponoszonego ryzyka) ${ }^{29}$.

Konsekwencją przyjęcia teorii własności jest uznanie bilansu za najważniejsze spośród sprawozdań finansowych (ujęcie statyczne). Uważnie śledzone są interakcje pomiędzy firmą a otoczeniem (w kontekście społecznym), szczególnie zaś wspomniana już dystrybucja dochodów. Jak podkreśla Taheri, w modelu tym dochodowość przedsiębiorstwa jest pochodną odpowiedzialnego zarządzania aktywami i pasywami, zachowania równowagi między majątkiem a zobowiązaniami ${ }^{30}$.

\footnotetext{
${ }^{26} \mathrm{~J}$. Adamek wskazuje, że skoro celem rachunkowości islamskiej jest dostarczenie informacji istotnych z punktu widzenia zakat, świadczy to o słabości powiązań tego zadania, stawianego sprawozdawczości muzułmańskiej, z pojęciem obiektywności. J. Adamek, Kulturowe uwarunkowania..., s. 53.

${ }^{27}$ Takich jak sposób traktowania pracowników, rzetelne opłacanie podatków, działalność charytatywna, wpływ na środowisko naturalne.

${ }^{28}$ N. Baydoun, R. Willett, Islam and Accounting: Ethical Issues in the Presentation of Financial Information, „Accounting, Commerce \& Finance: the Islamic Perspective” 1997, vol. 1, nr 1, s. 19.

${ }^{29}$ Za: M. Taheri, op. cit., s. 4-5. Cf. A. Belkaoui, Accounting Theory, Dryden Press, New York 1993, s. 166 i n., 233; M. Khan, Accounting Issues and Concepts for Islamic Banking, International Conference on Developing Accounting Standards for Islamic Banks IIB I, London 1994, s. 5 i n.

${ }^{30}$ M. Taheri, op. cit., s. 5.
} 
Postrzeganie działalności gospodarczej przez pryzmat przychodów i kosztów ukierunkowuje bowiem rachunkowość na zarządzanie kosztami (dążenie do ich minimalizacji), co prowadzi częstokroć do ,nieludzkich zachowań" ${ }^{31}$. Podstawą dla wyceny majątku nie powinny być zasady niezgodne z nauką islamu, a więc koszt historyczny, zatem wycena odbywać się powinna np. według aktualnych cen sprzedaży (current exit price) ${ }^{32}$.

Jedną z fundamentalnych różnic między ekonomią zachodnią, a islamską, znajdującą swe odbicie w ukształtowaniu systemu rachunkowości, jest podejście do kwestii podatkowych. W krajach zachodnich podatek traktowany jest jako obciążenie, którego w miarę możliwości przedsiębiorstwo powinno unikać (co wynika z nastawienia na zysk i oceny efektywności działalności gospodarczej z tej perspektywy). Dla muzułmanina zakat jest ,jałmużną” (dosłowne znaczenie tego słowa), należną uboższym od tych, których majątek przekracza określony limit. Pobiera ją i dystrybuuje państwo, realizując zasadę sprawiedliwości społecznej; uchylanie się od podatku lub próby jego obniżenia są zarówno grzechem, jak i zubożeniem społeczeństwa i nie mogą być uznane za legalne. Obowiązek zapłaty zakat powoduje szereg problemów dla księgowości, ponieważ zasady zakat są niezgodne z ogólnie przyjętą praktyką rachunkowości (GAAP). Główny problem stanowi niezgodność całej koncepcji zakat z zasadą ostrożności. Głosi ona, że przy wycenie należy się upewnić, iż wartość aktywów i przychodów nie jest zawyżona, a zobowiązania i koszty - zaniżone. Zaniżenie wartości aktywów oznaczałoby jednak mniejszą należność podatkową. W kontekście omówionego powyżej podejścia do kwestii podatkowych (islam zachęca do szczodrobliwości) byłoby to grzechem. Siłą rzeczy księgowy muzułmański skupia się na tym, by nie zaniżyć wartości aktywów, ani nie zawyżyć wartości zobowiązań, postępując wbrew zasadzie ostrożności. Kolejny problem stanowi sposób wyceny zapasów i należności. Zakat jest opłacany jedynie od nadwyżki aktywów ${ }^{33}$ :

(1) stanowiących rzeczywistą własność firmy,

(2) produktywnych,

(3) znajdujących się w posiadaniu przedsiębiorstwa przez cały rok.

Zgodnie z ogólnie przyjętymi zasadami rachunkowości, zapasy powinny być wyceniane według niższej z dwóch wartości: kosztu wytworzenia lub wartości rynkowej (zwykle wartość sprzedaży netto, rzadziej wartość nabycia lub wartość odtworzeniowa). W praktyce, jak zauważa $\mathrm{S}$. Rahman, powołując się na Clarke'a ${ }^{34}$, w wycenie bilansowej stosowany jest najczęściej koszt wytworzenia. Tymczasem dla celów zakat istotna jest tylko cena sprzedaży (selling price). Muzułmanie stosując się do zaleceń GAAP w wycenie zapasów, łamaliby przepisy własnego prawa ${ }^{35}$. Jeśli

\footnotetext{
${ }^{31}$ J. Adamek, Kulturowe uwarunkowania..., s. 54.

${ }^{32}$ M. Taheri, op. cit., s. 5. Cf. T.E. Gambling, R.A.A. Karim, Business and Accounting Ethics in Islam, Mansell, London 1991, s. 39, 84, 88-99.

${ }^{33}$ S. Rahman, op. cit., s. 4.

${ }^{34}$ Ibidem. Cf. F. Clarke, R. Craig, S. Hamid, Physical Asset Valuation and Zakat: Insights and Implications, „Advances in International Accounting” 1996, vol. 9, s. 204.

${ }^{35}$ S. Rahman, op. cit., s. 4.
} 
chodzi o wycenę należności, zakat jest płatny wyłącznie od należności netto. Obowiązek podatkowy zakat nie uwzględnia istnienia należności wątpliwych i nie tworzy się rezerw na należności nieściągalne ${ }^{36}$.

Konieczność przestrzegania prawa Sharia'h powoduje, że księgowi islamscy mają problemy z przestrzeganiem również innych zasad rachunkowości, przyjętych powszechnie w cywilizacji Zachodu, jak np. zasady pomiaru pieniężnego. Prowadzi ona do ograniczenia zakresu informacji istotnych dla islamskiego odbiorcy sprawozdania, a niedających się wyrazić tym miernikiem. Powyższe różnice wynikają $\mathrm{z}$ alternatywnego $\mathrm{w}$ stosunku do zachodniego sposobu definiowania pieniądza w ekonomii islamskiej. Pieniądz nie jest tu określany jako „kapitał”, lecz jako „środek wymiany”. „Kapitał” stanowią bowiem wyłącznie zasoby, które mogą zostać użyte w procesie produkcyjnym ${ }^{37}$. W warunkach inflacji pieniądz traci atrybut ,uczciwej” i ,sprawiedliwej” jednostki pomiaru. Islamscy ekonomiści proponują zatem wykorzystywanie raczej ceny odtworzenia, modelu aktualnej wartości albo oparcie wartości pieniądza na parytecie kruszców szlachetnych ${ }^{38}$. Również zasada memoriałowa, będąca jedną z najważniejszych zasad rachunkowości, budzi kontrowersje. Zwolennicy tej zasady argumentują, że stanowi ona narzędzie poprawnego szacowania bogactwa, podstawę do obliczania zakat, harmonizuje też z większością islamskich produktów finansowych. Liczni przeciwnicy wskazują jednak, że zgodnie z zasadą memoriału podmiot zmuszany jest do odprowadzania zakat od majątku, którego realnie nie otrzymał. Zasada ta podważa też podstawowe założenia kontraktu mudaraba, bazującego na dystrybucji zysków kasowych, który jest powszechnie stosowany w umowach gospodarczych w krajach islamskich. Jego popularność wynika z fundamentalnego zakazu pobierania odsetek. Uzasadnieniem jest przekonanie, że kapitał należy inwestować produktywnie ${ }^{39}$. Zgodnie z przekazem religijnym, zarabiać wolno wyłącznie własną pracą i nie można pomnażać swego kapitału w oparciu o wykorzystanie czyjejś własności. W praktyce zatem nie może mieć zastosowania stopa procentowa. Kładąc nacisk na czerpanie dochodów z wymiany, które będąc dochodem ex-post stanowią wyznacznik sukcesu gospodarczego i pomnażają bogactwo, doktryna islamu odsetki traktuje jako dochód exante, wynagrodzenie nienależne i niemoralne, gdyż ustalane bez związku z rezultatem przedsięwzięcia gospodarczego, którego dotyczą ${ }^{40}$. Dlatego kluczowym elementem bankowości islamskiej, prócz udostępniania nieoprocentowanych fundu-

\footnotetext{
${ }^{36}$ Ibidem.

${ }^{37}$ Pieniądz nie spełnia wymogów takiej definicji „kapitału” (ani jako banknot, ani jako moneta - ma wartość tylko jako materiał, który posłużył do jego wytworzenia). Cf. M.A. Bonca, op. cit., s. 84; M. Czerny, op. cit., s. 21-22; M.H. Kamali, Tas 'ir (Price Control) in Islamic Law, ,The American Journal of Islamic Sciences" 1994, vol. 11, nr 1, s. 25-36; S.M. Behesh'ti, Islamic Economic, Fajar Press, Teheran 1992, s. 126; A. Zaman, Islamic Economics: A Survey of the Literature, International Institute of Islamic Economics, Religion and Developement Research Program, Lead Research Institution: International Developement Department, University of Birmingham 2005, s. 27, s. 31 i n.

${ }^{38}$ J. Adamek, Uwarunkowania kulturowe..., s. 59-60.

${ }^{39}$ M. Taheri, op. cit., s. 5-6; S. Rahman, op. cit., s. 5-6.

${ }^{40}$ J. Adamek, Uwarunkowania kulturowe..., s. 46.
} 
szy, jest koncepcja podziału zysków i strat ${ }^{41}$. Zgodnie z zasadami Sharia'h obie strony transakcji muszą dzielić między siebie zarówno zyski, jak i straty, wynikające $\mathrm{z}$ danego przedsięwzięcia ${ }^{42}$.

Reasumując, jakkolwiek praktyczny wymiar rachunkowości postrzegany jest w krajach islamskich jako swoista technika rejestrowania transakcji, to jej założenia teoretyczne różnią się zasadniczo od zachodniego, amerykańsko-brytyjskiego modelu tejże. Powoduje to szereg trudności w dostosowaniu rachunkowości islamskiej do obowiązujących ,globalnych standardów” (GAAP czy IFRS). Z uwagi na bezwzględną konieczność przestrzegania norm religijnych, odmienność celów sprawozdań finansowych i hierarchię ich użytkowników w krajach muzułmańskich, „konwencjonalne” sprawozdania finansowe nie mogą tu mieć w gruncie rzeczy właściwego zastosowania. Właśnie stąd wynika konsekwentne wypracowywanie w ostatnich latach przez Accounting and Auditing Organization for Islamic Financial Institutions ,własnych” standardów rachunkowości, zgodnych z Sharia ’h, które w założeniu mają obowiązywać we wszystkich krajach muzułmańskich.

\section{Konfucjanizm a azjatyckie modele rachunkowości}

Konfucjanizm jest systemem filozoficzno-religijnym związanym mocno z kontynentem azjatyckim (podobnie jak buddyzm czy islam). Cywilizacja Azji różni się zaś od zachodniej wyjątkowo silnym systemem powinności i obowiązków, wiążących członków społeczności ${ }^{43}$. Nauki Konfucjusza wywarły silny wpływ nie tylko na kształt organizacji społecznej, w tym na sposób funkcjonowania gospodarki, ale także na postrzeganie roli systemu rachunkowości w działalności gospodarczej i tym samym kształt tego systemu informacyjno-kontrolnego. Nauki te można generalnie sprowadzić do następujących te $\mathrm{z}^{44}$ :

(1) stabilność społeczeństwa jest oparta na nierówności relacji międzyludzkich;

(2) rodzina stanowi prototyp organizacji społecznej,

(3) „cnotliwe zachowanie” sprowadza się do hasła: traktuj innych tak, jak sam chciałbyś być potraktowany;

(4) cnota w odniesieniu do ludzkich celów życiowych polega na pielęgnowaniu zdolności, zdobywaniu wykształcenia, ciężkiej pracy i oszczędności (rozumianej jako niewydawanie więcej, aniżeli to konieczne).

\footnotetext{
${ }^{41}$ PLS - profit and loss sharing theory.

${ }^{42}$ Cf. Z. Iqbal, A. Mirakhor, Islamic Banking, International Monetary Fund, D.C., Washington 1987, s. 112 i nast.; M.A. Bonca, op. cit., s. 83-85; Accounting and Auditing Organisation for Islamic Financial Institutions, Sharia Standards for Islamic Financial Institutions, Bahrain 2010.

${ }^{43}$ Cf. K. Gawlikowski, Jednostka i władza w cywilizacji wschodnioazjatyckiej [w:] Korea: doświadczenia i perspektywy, red. K. Gawlikowski, E. Potocka, Wyd. Adam Marszałek, Toruń 2001; K. Gawlikowski, Konfucjański model państwa w Chinach, Instytut Studiów Politycznych Polskiej Akademii Nauk, Warszawa 2009, http://www.isppan.waw.pl/subpage/cbap/wp/isp_konfucj_model_panstwa.pdf (data dostępu: 20.05.2015); Azja-Pacyfik. Obraz gospodarczy regionu, red. B. Drelich-Skulska, Wydawnictwo Akademii Ekonomicznej im. Oskara Langego we Wrocławiu, Wrocław 2007.

${ }^{44}$ B. Drelich-Skulska, op. cit., s. 72. Cf. J. Mikułowski-Pomorski, Komunikacja międzykulturowa. Wprowadzenie, Wydawnictwo AE, Kraków 1999, s. 108.
} 
W oparciu o te założenia kraje azjatyckie wypracowały elementy systemu gospodarczego jawiące się jako wspólne dla całego kontynentu (niezależnie od panującego w danym kraju ustroju polityczno-gospodarczego). Do najistotniejszych spośród tych elementów należą $a^{45}$ :

(1) kolektywizm (rozwój jednostki i jej działanie odbywa się w otoczeniu grupy, która jest punktem odniesienia i wsparcia),

(2) dom (wszelkie powiązania społeczne opierają się na koncepcji powiązań rodzinnych, hierarchii rodzinnej i rodzinnej odpowiedzialności),

(3) lojalność i obowiązkowość (zajmujący wyższą pozycję w hierarchii są moralnie zobowiązani do odpowiedzialności za podwładnych).

W powiązaniu z wartościami społecznymi powszechnie akceptowanymi w Azji, takimi jak:

(1) porządek społeczny i dobra organizacja,

(2) poszanowanie tradycji,

(3) harmonia w społeczeństwie,

(4) poszanowanie władzy,

(5) zapewnienie odpowiedzialności funkcjonariuszy publicznych,

(6) swoboda wypowiedzi,

elementy te determinują nie tylko sposób funkcjonowania społeczeństw, ale i prowadzenia biznesu ${ }^{46}$. Konkurencja traktowana jest jako czynnik nieproduktywny, gdyż konfucjanizm akcentuje współpracę (jako wyraz harmonii, która powinna cechować społeczeństwo). Podkreśla przy tym, iż zysk i posiadanie nie powinny być motywem działania człowieka (warto zwrócić uwagę, że konkurencja „w branży” na rynkach azjatyckich jest znacznie łagodniejsza, niż ma to miejsce w świecie zachodnim).

Bloom i Solotko wskazują na związki pomiędzy doktryną konfuncjanizmu i rachunkowości - w pierwszym rzędzie na stałość historyczną formy i struktury rachunkowości, przystosowanie jej do tradycyjnych praktyk, co wynika z głębokiego szacunku Azjatów dla tradycji w ogóle ${ }^{47}$. Warto podkreślić, że aż do lat dwudziestych ubiegłego wieku powszechne było w Azji np. stosowanie zapisu trójkolumnowego, jako uświęconego tradycją modelu techniki raportowania finanso$w_{e g o}{ }^{48}$. Stąd wynika również rodzaj informacji, dostarczanych przez azjatyckie systemy rachunkowości - głównie o charakterze makroekonomicznym (podobnie jak $\mathrm{w}$ islamie, odbiorcą są bowiem przede wszystkim organy administracji państwowej, na co wpływ mają - obok uwarunkowań historycznych - również skłonności kolektywistyczne i szacunek dla hierarchii w krajach azjatyckich). Z poszanowania dla tradycyjnych rozwiązań wynika także charakter statyczny azjatyckich sprawoz-

\footnotetext{
${ }^{45}$ M.R. Nowakowski, Zarządzanie operacjami zagranicznymi przedsiębiorstw japońskich, Zakład Nauk Zarządzania PAN, Warszawa 1990, s. 111.

${ }^{46}$ M. bin Mohamad, Rozważania o wartościach azjatyckich, „Azja-Pacyfik” 1999, t. 2, s. 157.

${ }^{47}$ R. Bloom, J. Solotko, The Foundation of Confucianism in Chinese and Japanese Accounting, ,Accounting, Business \& Financial History" 2003, vol. 13, nr 1, s. 30, doi: 10.1080/09585200210164566c.

${ }^{48}$ S.S. Gao, M. Handley-Schachler, The Influences of Confucianism, Feng Shui and Buddhism in Chinese Accounting History, ,Accounting, Business \& Financial History” 2003, vol. 13, nr 1, s. 55, doi: 10.1080/ $09585200210164566 \mathrm{~d}$.
} 
dań finansowych (dzisiejszy bilans traktowany jest jak historyczny „spis rządowy” dostarczany namiestnikowi prowincji czy urzędnikowi „dworu” przez pomniejszych urzędników), rzadko uzupełniany o pomiar i kalkulację zysków i strat.

Wpływ doktryny konfucjańskiej dostrzegalny jest także, jeśli chodzi o prawne uregulowanie rachunkowości w krajach azjatyckich. Regulacja ta odbywa się zazwyczaj w oparciu o minimalną kodyfikację zasad i regulacji stojących na straży dobra społecznego (postrzegane jest ono przez pryzmat relacji pomiędzy rolą i znaczeniem osobistego rozwoju, lojalnością a etyką i moralnością jednostki, jako czynników determinujących i zwiększających korzyści odnoszone przez społeczeństwo).

Kolejną z cech charakterystycznych dla systemu rachunkowości i praktyk księgowych w krajach Azji, które można powiązać z systemem zasad konfucjańskich, jest konserwatyzm i nadmierne unikanie ryzyka (przywiązanie do kosztu historycznego, wygładzanie dochodów zróżnicowanych w czasie).

Pewną sprzeczność można zauważyć pomiędzy cechującymi działania biznesowe Azjatów nepotyzmem i dyskrecją (co wynika z konfucjańskiego podporządkowania cnocie lojalności - wobec państwa, rodziny, przyjaciół), a podejściem do ujawniania sprawozdań finansowych, które z kolei oparte na wartościach takich jak uczciwość, prawdomówność. Uczciwość i prawdomówność nie pozostają generalnie w sprzeczności z lojalnością, mogą jednak okazać się sprzeczne z dyskrecją i szacunkiem winnym starszym, przełożonym, czy wreszcie członkom rodziny (cnota stawiana bardzo wysoko w systemie wartości konfucjańskich). Zasadniczo jednak kontrolna funkcja rachunkowości jest akceptowana. Kontrola (np. ksiąg rachunkowych) jest usprawiedliwiona (nie jest sprzeczna z koncepcją lojalności i nie podważa zaufania), gdyż transparentność informacji, ich weryfikowalność, sprzyja otwartości, która również należy do cnót konfucjańskich. Sprzyja również zachowaniu porządku społecznego i odpowiedzialności funkcjonariuszy publicznych.

Ogólnie rzecz biorąc, rachunkowość, podobnie jak ludzie zajmujący się nią zawodowo, podlegają w tak zorganizowanym społeczeństwie swoistej dyskryminacji. Wynika to z założenia, że każdy członek społeczeństwa powinien umieć zadbać osobiście o swe finanse i transakcje handlowe. Przy silnej hierarchizacji pozycji społecznej cechującej społeczeństwa Azji, zawód księgowego oceniany jest stosunkowo nisko, jego misja - podobnie jak rola systemu rachunkowości - jest służebna (rola rachmistrza), a w wielu przypadkach postrzegana jako zbędna. Rachunkowość dostarczać ma danych przede wszystkim w skali makro, użytecznych dla władz, dających rozeznanie w stanie posiadania i kondycji całej gospodarki i dobrobycie społeczeństwa (służyć dobru społecznemu). Stosunkowo najlepiej postrzegana i rozumiana jest tu jej funkcja kontrolna.

\section{Zakończenie}

Powyższy krótki przegląd funkcjonujących w różnych kręgach kulturowych systemów rachunkowości w kontekście panujących w nich zasad religijnych, wskazuje wyraźnie, że ukształtowały się one odmiennie, w zależności od wpływów czynni- 
ków kulturowych. Jak się wydaje, spośród trzech omówionych w artykule systemów rachunkowości najsłabiej obecnie powiązana z zasadami religijnymi jest rachunkowość uznawana powszechnie za „konwencjonalną”, a konkretnie jej model brytyjsko-amerykański. Jednak, jak już wskazano, uznane za konieczność w przypadku rachunkowości zachowanie wysokich standardów etycznych pozwala wskazać na związek z religią, w przypadku modelu konwencjonalnego - z chrześcijaństwem. Większość systemów etycznych jest bowiem w swych podstawowych założeniach spójna z jego przesłaniem, a część z nich wyrosła na gruncie doktryny religijnej. Systemy rachunkowości, które rozwinęły się w krajach azjatyckich, są silnie powiązane z wyznawanymi tam powszechnie doktrynami religijnymi i filozoficznymi, natomiast najsilniej religia odcisnęła swoje piętno na islamskim modelu rachunkowości. Ponieważ jednak rachunkowość jako system nie powstała i nie rozwijała się „,sama dla siebie”, lecz w ramach systemu gospodarczego, nie ulega wątpliwości, że czynnik religijny miał w przeszłości (i ma obecnie, przynajmniej w niektórych kręgach kulturowych) wpływ na jej ukształtowanie (podobnie jak miał wpływ na ukształtowanie się odmiennych modeli gospodarczych). Można dyskutować jedynie nad siłą tego oddziaływania. Rodzi się jednocześnie pytanie o sensowność daleko posuniętej standaryzacji rachunkowości i o istotną możliwość jej konwergencji. Zwolennicy procesu standaryzacji wskazują na jego zalety: ma on polepszyć zachowanie podstawowych dla księgowości zasad - spójności i porównywalności. Pozwoliłoby to inwestorom zagranicznym odbierać treść sprawozdania finansowego w sposób spójny, umożliwiający podejmowanie lepszych decyzjii ${ }^{49}$. Powstaje jednak pytanie, czy harmonizacja norm i zasad, którym podlega system rachunkowości, posunięta wystarczająco daleko, nie wpłynie, wbrew założeniom, na pogorszenie przydatności sprawozdań finansowych, a tym samym na ich jakość. Wartości kulturowe, w tym religia, ukształtowały odmiennie zarówno systemy gospodarcze, jak i kulturę organizacyjną, a jak próbuje dowieść niniejszy artykuł, także praktyki rachunkowości. W odniesieniu do sprawozdawczości finansowej, różny jest krąg jej odbiorców i różne oczekiwania są formułowane co do informacji, których powinna dostarczać. Różnic tych nie da się łatwo pogodzić, wdrażając uniwersalny standard rachunkowości jako swoisty wzór do naśladowania dla wszystkich. Warto przy tym zauważyć, że proces standaryzacji rachunkowości polega jak na razie - na swoistym ,narzucaniu” globalizującemu się światu zachodnich praktyk księgowych. Oderwanie rachunkowości od jej kontekstu gospodarczo-kulturowego spowoduje stworzenie modelu, który w dalszym ciągu największą użyteczność będzie miał dla odbiorcy „,zachodniego”. Co więcej - obraz przedsiębiorstwa zawarty w sprawozdaniach finansowych, choć łatwo dla tego odbiorcy zrozumiały, może być zafałszowany, nie uwzględni bowiem w żaden sposób specyfiki społecznych, politycznych, prawnych i ekonomicznych uwarunkowań środowiska, $\mathrm{w}$ jakim firma działa ${ }^{50}$. Standaryzacja $\mathrm{w}$ tym kształcie, jaki przyjmuje obecnie, nie

\footnotetext{
${ }^{49}$ M. Zarzeski, Spontaneous Harmonization Effects of Culture and Market Forces on Accounting Disclosure Practices, „Accounting Horizons” 1996, vol. 10, nr 1 [za:] M. Young, op. cit., s. 40.

${ }^{50} \mathrm{O}$ potrzebie uwzględnienia tych czynników, podobnie jak ,,potrzeb społeczeństwa”, pisał już Mueller, a ostatnio Oluku i Ojeka. Także Zarzeski, omawiając zalety harmonizacji systemu rachunkowości, zwraca uwagę na fakt, że „,kraje mają już ustalone rynki i potrzeby finansowe”, a także „opracowane
} 
jest uznawana za integrację, a w wielu krajach odbierana jest jako arogancka próba narzucania własnych rozwiązań, bez oglądania się na odmienne wzorce kulturowe, jakby w przekonaniu, że kultura zachodnia i wypracowane przez nią standardy są lepsze od innych ${ }^{51}$.

Wydaje się, że te kwestie w przyszłości zyskają jeszcze na znaczeniu - w świecie różnic kulturowych uniwersalny standard rachunkowości jest niezwykle trudny, o ile w ogóle możliwy do wypracowania, a proces harmonizacji rachunkowości powinien uwzględniać ten fakt tam, gdzie jest to niezbędne. W przeciwnym razie nie spełni swych celów. Nawet w epoce postępującej globalizacji nie można bowiem spodziewać się, że całe społeczeństwa dokonają szybkiego „przeorientowania” podstawowych systemów wartości.

\section{Bibliografia}

Accounting and Auditing Organisation for Islamic Financial Institutions, Sharia Standards for Islamic Financial Institutions, Bahrain 2010.

Adamek J., Rachunkowość w kręgu kultury islamskiej, „Zeszyty Teoretyczne Rachunkowości" 2009, t. 49 (105), s. 7-17.

Adamek J., Kulturowe uwarunkowania krajowych systemów rachunkowości w świetle koncepcji wymiarów subkultury rachunkowości S. Graya, „Zeszyty Teoretyczne Rachunkowości” 2011, t. 62 (118), s. 7-22.

Adamek J., Kultura a rachunkowość [w:] Finanse i rachunkowość - teoria i praktyka, Prace Naukowe Uniwersytetu Ekonomicznego we Wrocławiu, nr 193, Wrocław 2011.

Adamek J., Kulturowe uwarunkowania rachunkowości w świetle założeń i praktyki rachunkowości islamskiej i chińskiej, CeDeWu, Warszawa 2012.

Afifuddin H.B., A.K. Siti-Nabiha, Towards Good Accountability: The Role of Accounting in Islamic Religious Organisations, „World Academy of Science, Engineering and Technology. International Journal of Social, Behavioral, Educational, Economic, Business and Industrial Engineering" 2010, vol. 4, nr 6, s. 1141-1147.

Baydoun N., R. Willett, Islam and Accounting: Ethical Issues in the Presentation of Financial Information, ,Accounting, Commerce \& Finance: the Islamic Perspective” 1997, vol. 1, nr 1, s. 1-25.

Behesh'ti S.M., Islamic Economic, Fajar Press, Teheran 1992.

Belkaoui A., Accounting Theory, Dryden Press, New York 1993.

Biblia Tysiaclecia, wyd. III, Wydawnictwo Pallottinum, Poznań-Warszawa 1982.

\footnotetext{
standardy rachunkowości” - wszystko to w oparciu o „kontekst kulturowy”. G. Mueller, op. cit.; M.D. Oluku, S. Ojeka, The Challenge of Culture to International Financial Reporting Standards Convergence, „Interdisciplinary Journal of Contemporary Research in Business” 2011, vol. 2, nr 12, s. 917; M. Zarzecki, op. cit. [za:] M. Young, op. cit., s. 40.

${ }^{51}$ M. Young, op. cit., s. 41. Cf.: S. Hamid, R. Craig, F. Clarke, Religion: A Confounding Cultural Element in the International Harmonization of Accounting?, „Abacus” 1993, vol. 29, nr 2, s. 131-148, doi: 10.1111/j.1467-6281.1993.tb00427.x.
} 
Bloom R., J. Solotko, The Foundation of Confucianism in Chinese and Japanese Accounting, „Accounting, Business \& Financial History” 2003, vol. 13, nr 1, s. 27-40, doi: $10.1080 / 09585200210164566 \mathrm{c}$.

Bonca M.A., Islamskie instrumenty finansowe, Wydawnictwa Akademickie i Profesjonalne, Akademia Leona Koźmińskiego, Warszawa 2010.

Carmona S., M. Ezzamel, Accounting and religion: A historical perspective, „Accounting History" 2006, vol. 11, nr 2, s. 117-127, doi: 10.1177/1032373206063109.

Chapra M.U., The Islamic Welfare State and its Role in the Economy [w:] Studies in Islamic Economics, red. A. Khurshid, Redwood Burn, Leicester 2006.

Clarke F., R. Craig, S. Hamid, Physical Asset Valuation and Zakat: Insights and Implications, „Advances in International Accounting” 1996, vol. 9, s. 109-208.

Czerny M., Wpływ zasad religijnych islamu na sprawozdania finansowe - zarys problemu, Teoria i historia rachunkowości, materiały konferencyjne UEP „Rachunkowość Warta Poznania”, Poznań 2015.

Diaconau P., N. Norman, Accounting Research from the Globalization Perspective, „International Journal of Human and Social Sciences" 2006, vol. 1, nr 1.

Azja-Pacyfik. Obraz gospodarczy regionu, red. B. Drelich-Skulska, Wydawnictwo Akademii Ekonomicznej im. Oskara Langego we Wrocławiu, Wrocław 2007.

Gambling T.E., R.A.A. Karim, Business and Accounting Ethics in Islam, Mansell, London 1991.

Gao S.S., M. Handley-Schachler, The influences of Confucianism, Feng Shui and Buddhism in Chinese Accounting History, „Accounting, Business \& Financial History” 2003, vol. 13, nr 1, s. 41-68, doi: 10.1080/09585200210164566d.

Gawlikowski K., Jednostka $i$ władza w cywilizacji wschodnioazjatyckiej [w:] Korea: doświadczenia i perspektywy, red. K. Gawlikowski, E. Potocka, Wyd. Adam Marszałek, Torun 2001.

Gawlikowski K., Konfucjański model państwa w Chinach, Instytut Studiów Politycznych Polskiej Akademii Nauk, Warszawa 2009, http://www.isppan.waw.pl/subpage/cbap /wp/isp_konfucj_model_panstwa.pdf.

Gray S.J., Towards a Theory of Cultural Influence on the Development of Accounting System Internationally, ,Abacus” 1988, vol. 24, nr 1, s. 1-15, doi: 10.1111/j.1467-6281.19 88.tb00200.x.

Hamid S., R. Craig, F. Clarke, Religion: A Confounding Cultural Element in the International Harmonization of Accounting?, „Abacus” 1993, vol. 29, nr 2, s. 131-148, doi: 10.1111/j.1467-6281.1993.tb00427.x.

Hofstede G., Culture's Consequences: International Differences in Work-Related Values, Sage, Beverly Hills-London 1980.

Hofstede G., Cultural Dimensions in Management and Planning, „Asia Pacific Journal of Management" 1984, vol. 1, nr 2, s. 81-99.

Holton R., Economy and Society, Routledge, London-New York 1992.

Iqbal Z., A. Mirakhor, Islamic Banking, International Monetary Fund, D.C., Washington 1987.

Jaworska E., Specyfika rachunkowości islamskiej. Wybrane zagadnienia [w:] Finanse, rynki finansowe, ubezpieczenia, Zeszyty Naukowe Uniwersytetu Szczecińskiego nr 32, Wydawnictwo Uniwersytetu Szczecińskiego, Szczecin 2011. 
Kamali M.H., Tas'ir (Price Control) in Islamic Law, „The American Journal of Islamic Sciences" 1994, vol. 11, nr 1.

Kamela-Sowińska A., Rachunkowość od antropologii do międzynarodowych standardów [w:] Rachunkowość w zarządzaniu jednostkami gospodarczymi, red. T. Kiziukiewicz, Katedra Rachunkowości Uniwersytetu Szczecińskiego, Katedra Rachunkowości Akademii Rolniczej w Szczecinie, Szczecin 2006.

Khan M., Accounting Issues and Concepts for Islamic Banking, International Conference on Developing Accounting Standards for Islamic Banks IIB I, London 1994.

Lehman G., Accounting, Accountability and Religion: Charles Taylor's Catholic Modernity and the Malaise of a Disenchanted World, Fourth Asia Pacific Interdisciplinary Research in Accounting Conference 2004, University of South Australia, School of Accounting, Singapore.

Maali B., Napier C., Accounting, Religion and Organisational Culture: The Creation of Jordan Islamic Bank, „Journal of Islamic Accounting and Business Research” 2010, nr 1(2), s. 6-11.

Mohamad M. bin, Rozważania o wartościach azjatyckich, „Azja-Pacyfik” 1999, t. 2, s. 157-168.

Mikułowski-Pomorski J., Komunikacja międzykulturowa. Wprowadzenie, Wydawnictwo AE, Kraków 1999.

Moin M.S., Financial Performance of Islamic Banking and Conventional Banking in Pakistan: A Comparative Study, „International Journal of Innovative and Applied Finance" 2013, vol. 1, nr 1, s. 1-22.

Mueller G., International Accounting, Macmillan, New York 1967.

Mutahhari M., Islamic Economic, Sadra Pub., Teheran 1993.

Nasr S.H., A Young Muslim's Guide to The Modern World, Cambridge 1993.

Nowakowski M.R., Zarzadzanie operacjami zagranicznymi przedsiębiorstw japońskich, Zakład Nauk Zarządzania PAN, Warszawa 1990.

Oluku M.D., S. Ojeka, The Challenge of Culture to International Financial Reporting Standards Convergence, „Interdisciplinary Journal of Contemporary Research in Business" 2011, vol. 2, nr 12, s. 914-924.

Onyebuchi V., Ethics in Accounting, „International Journal of Business and Social Science” 2011, vol. 2, nr 10, s. 275-276.

Rahman S., Islamic Accounting Standards 1997, http://www.ifew.com/insight/13036mon/ac cstds.htm.

Satava D., C. Caldwell, L. Richards, Ethics and Auditing Culture: Rethinking the Foundation of Accounting and Auditing, ,Journal of Business Ethics” 2006, vol. 64, nr 3, s. 271-284, doi: 10.1007/s10551-005-0556-y.

Al-Sadr M.B., Iqtisaduna (Our Economic), 2 ${ }^{\text {nd }}$ Edition, Teheran 1994.

Samad A., Performance of Interest-free Islamic Banks vis-à-vis Interest-based Conventional Banks of Bahrain, „IIUM Journal of Economics and Management” 2004, vol. 12, nr 2.

Shari'ati A., Abu Zar, (Companion of the Prophet), Ershad Pub., Teheran 1987.

Siddiqi M.N., Muslim Economic Thinking: A Survey of Contemporary Literature, The Islamic Foundation, United Kingdom 1981. 
Szczepankiewicz E.I., Wybrane aspekty i uwarunkowania realizacji zasad etyki przez audytorów wewnętrznych, „Monitor Rachunkowości i Finansów” 2007, nr 9.

Szczepankiewicz E.I., M. Dudek, Etyka $w$ działaniu audytora wewnętrznego [w:] Etyka $w$ procesie ksztatcenia i gospodarowania, red. A. Kamela-Sowińska, Zeszyty Naukowe Wyższej Szkoły Handlu i Rachunkowości w Poznaniu, Poznań 2007.

Taheri M.R., The Basic Principles of Islamic Economy and Their Effects on Accounting Standards-Setting, 2011, http://www.docstoc.com/docs/166485067/The-basic-princ iples-of-Islamic-economy-and-their-effects-on-accountingstandards-setting.

Wiseman T., A. Young, Religion: Productive or Unproductive?, „Journal of Institutional Economics" 2014, vol. 10, nr 1, s. 21-45, doi: 10.1017/S174413741300026X.

Young M., Cultural Influences on Accounting and Its Practices, 2013, http://digitalcommons.liberty.edu/cgi/viewcontent.cgi?article $=1396 \&$ context=honors.

Zaman A., Islamic Economics: A Survey of the Literature, International Institute of Islamic Economics, Religion and Developement Research Program, Lead Research Institution: International Developement Department, University of Birmingham 2005.

Zarzeski M., Spontaneous Harmonization Efects of Culture and Market Forces on Accounting Disclosure Practices, „Accounting Horizons” 1996, vol. 10, nr 1. 